\title{
High Frequency of Recombinant Genomes in HIV Type 1 Samples from Brazilian Southeastern and Southern Regions
}

\author{
MONICK LINDENMEYER GUIMARÃES, ${ }^{1}$ ALINE DOS SANTOS MOREIRA, ${ }^{1}$ REGINA LOUREIRO,${ }^{2}$ \\ BERNARDO GALVÃO-CASTRO, ${ }^{3}$ THE BRAZILIAN NETWORK FOR HIV ISOLATION AND \\ CHARACTERIZATION, and MARIZA GONÇALVES MORGADO ${ }^{1}$
}

\begin{abstract}
We describe the genetic variability of HIV-1 subtypes and recombinant genomes in samples from southeastern and southern Brazilian regions. Phylogenetic analysis of a subset of 34 samples $(8 \mathrm{~F}, 7 \mathrm{~B}, 7 \mathrm{C}, 2 \mathrm{D}, 1 \mathrm{~A}$, and $9 \mathrm{~B}^{\prime \prime}$ variant) based on the DNA sequencing of the $e n v$ gp120 and gp41, gag p17, and $n e f$ regions confirmed the presence of nine $(26.5 \%)$ potentially HIV -1 recombinant genomes. From the eight C2-V3 gp120 subtype F samples, only two seem to be pure F. One of the samples, classified as $B^{\prime \prime}$ in the C2-V3 gp120 and as B in gp41 had the gag and nef regions clustering with subtype C. Two of seven C2-V3 subtype $C$ samples presented distinct recombinant patterns as Bgag/Cenv/Bnef and Bgag/Cenv/Cnef. Putative recombinant breakpoints were obtained for three samples presenting discordant subtypes (F/B) between gp120 and gp41 env fragments showing that similar breakpoints could be observed between two unlinked samples (95BRRJ014 and 96BRRJ101). A higher degree of polymorphism was verified in the analysis of a subtype A sample (98BRRS058) in the C2-V3/gp41 env fragment. The intrasubtype $\mathrm{C}$ distance was found to be lower than that found for the other subtypes for all genomic regions. These data confirm that distinct HIV-1 subtypes and recombinant forms are actively participating in the Brazilian AIDS epidemic, and that the subtype $\mathrm{C}$ was introduced more recently into southern Brazil.
\end{abstract}

\section{INTRODUCTION}

$\mathbf{T}$ He HIV/AIDS PANDEmic is highly heterogeneous and dynamic and composed of distinct microepidemics occurring in different regions of the world. As of September 2001, 222,356 AIDS cases have been reported to the Brazilian Ministry of Health and, on average, 597,443 people are estimated to be living with HIV/AIDS in the country. ${ }^{1}$

The human immunodeficiency virus type 1 (HIV-1) exhibits an extraordinary degree of genetic variability and has been classified, based on phylogenetic relationships, into groups, subtypes, subsubtypes, and circulating recombinant forms (CRFs). Three distinct groups were described: $\mathrm{M}$ (major), which contains the majority of the pandemic HIV-1 strains; group O (outlier), with very highly divergent strains, ${ }^{2}$ and group $\mathrm{N}$ (new or non-M non-O), found in Cameroon ${ }^{3}$ and strongly related to SIV $_{\text {CPZ }}$ from chimpanzees from this country. ${ }^{4,5}$ Based on phylogenetic relationships, the $\mathrm{M}$ group has been further divided into nine subtypes (A-D, F-H, J, and $\mathrm{K}$ ) and, more recently, the $\mathrm{F}^{6}$ and $\mathrm{A}^{7}$ subtypes were divided into two subclades. Recombination events are responsible for the formation of HIV1 mosaic genomes, with distinct subtype signatures in different genomic regions. Some of them, designated as CRFs, were obtained from apparently unlinked isolates with the same intersubtype breakpoints and are actively participating in the global AIDS epidemic. ${ }^{8}$

Subtype B has been described as the predominant HIV-1 subtype in Brazil followed by $\mathrm{F}$ and $\mathrm{C}$ subtypes, respectively, occurring in high frequency in the southeastern and southern regions. ${ }^{9-13}$ Moreover, the V3 loop GWGR HIV-1 B" variant and potential mosaic genomes involving the recombination or dual infections between $\mathrm{B} / \mathrm{F}, \mathrm{B} / \mathrm{C}$, and $\mathrm{F} / \mathrm{D}$ subtypes have been previously described by our group and other groups. ${ }^{14-17}$ The presence of D and A subtypes has already been demonstrated as isolated cases in the country. ${ }^{18,19}$

The aim of this study was to evaluate HIV-1 samples, ob-

\footnotetext{
${ }^{1}$ Department of Immunology, Oswaldo Cruz Institute, FIOCRUZ, Rio de Janeiro, Brazil.

${ }^{2}$ Public Healthy Secretariat of RS State, Porto Alegre, RS, Brazil.

${ }^{3}$ Advanced Public Health Laboratory, Gonçalo Muniz Research Center, FIOCRUZ, Bahia, Brazil.
} 
tained from Brazilian regions known for bearing high frequencies of different HIV-1 subtypes, to identify and characterize the presence of recombinant intersubtype genomes.

\section{MATERIALS AND METHODS}

\section{Virus strains}

A set of 34 samples, previously subtyped by envHMA, ${ }^{11,12,18}$ was obtained from two geographic regions of Brazil, characterized for the presence of more than one prevalent subtype. HIV-1 samples from southern Brazil are part of an ongoing study (R. Loureiro, unpublished data). For the discrimination of the GWGR-B" subtype B variant, the FokI restriction fragment length polymorphism(RFPL) was carried out as previously described. ${ }^{14}$ For the present study eight samples from subtype $\mathrm{F}$, seven from $\mathrm{B}$, seven from $\mathrm{C}$, two from $\mathrm{D}$, one from $\mathrm{A}$, and nine corresponding to the $\mathrm{B}$ " Brazilian subtype $\mathrm{B}$ variant were selected for DNA sequencing and phylogenetic analysis based on the env C2-V3 gp120 and gp41 regions, gag $\mathrm{p} 17$, and $n e f$ region.

\section{PCR amplification of the target sequences}

DNA samples $(\approx 1 \mu \mathrm{g})$ were PCR amplified by a nested protocol in a Perkin Elmer 480 or 9600 Thermal Cycle. PCR reactions were performed in a volume of $100 \mu$ l containing 10 $\mathrm{mM}$ Tris- $\mathrm{HCl}$ (pH 8.3), $50 \mathrm{mM} \mathrm{KCl}, 200 \mathrm{mM}$ of each dNTP, $20 \mathrm{pmol}$ of each primer, $1.25 \mathrm{mM} \mathrm{MgCl}_{2}$ and $2.5 \mathrm{U}$ Taq polymerase (Pharmacia Fine Chem., Sweden). The env C2-V3 PCR amplification was performed as previously described, ${ }^{20}$ using ED3/ED14 and ED31/ED33, respectively, as outer and inner primer sets. The gp41 PCR amplification was obtained by a nested protocol ${ }^{20}$ using ED3120/MM1(TGGTGAATATCCCTGCCTAA/HIV-1 HXB2 genome positions 8446 to 8365$)^{21}$ and $\mathrm{ES}^{20}{ }^{-M M} 4$ (CCTCCTACTATCATTATGAA/HXB2 positions 8276 to 8295 ) as outer and inner primer sets. MM oligonucleotides were designed for this study. The $g a g$ p 17 nested PCR amplification protocol ${ }^{21}$ was performed using GAG1 ${ }^{22} / \mathrm{MZ}^{2} 4^{23}$ and $\mathrm{GAG} 2^{22} / \mathrm{MZ1} 4^{23}$ as outer and inner primer sets. The nested PCR amplification of the nef region was obtained based on a previously described protocol, ${ }^{17}$ using specific nef outer and inner primers described elsewhere. ${ }^{24}$

\section{Direct DNA sequencing of PCR products}

Five microliters (50-150 ng of DNA) of PCR-amplified DNA was submitted to enzymatic treatment with $1 \mu$ l of shrimp alkaline phosphatase $(10 \mathrm{U} / \mu \mathrm{l})$ and $1 \mu \mathrm{l}$ of exonuclease I (2 $\mathrm{U} / \mu \mathrm{l})$ hydrolytic enzymes according to the manufacturer (Sequenase Version 2.0 DNA Polymerase, Amersham Pharmacia Biotech, Cleveland, OH). Immediately after this treatment, nucleotide sequences were obtained by the automated method (DNA sequencer model 377; Applied Biosystems, Foster City, CA) using a Big Dye Terminator kit (Applied Biosystems, Foster City, CA). The PCR products obtained for the env C2-V3, gag p17, and nef regions were sequenced in both senses using the PCR forward and reverse inner primers specified above. MM5 (TGAGGGACAATTGGAGAAGTG/HXB2 positions 7648-7668) and MM4 oligonucleotides were respectively used as forward and reverse $e n v$ gp41 sequencing primers. Edition of the nucleotide sequences and the translation of the predicted amino acid sequences were performed with the University of Wisconsin Genetic Computer Group (GCG) package. ${ }^{25}$

\section{Phylogenetic tree analysis}

DNA sequences were aligned by using CLUSTAL W. ${ }^{26}$ The alignments were edited manually for minor adjustments. Phylogenetic tree constructions were performed using the neighbor-joining method ${ }^{27}$ with the Kimura two-parameter method for distance correction, and the reliability of the branching orders were determined by the 100 times bootstrap. Only bootstrap values above $70 \%$ were specified in the major subtype branches. The final trees were visualized using the TreeView program. ${ }^{28}$ The intrasubtype and intersubtype distances were calculated using the Kimura two-parameter correction with pairwise gap deletion based on the MEGA program.

\section{gp120-C2-gp41 sequencing and intersubtype recombinant analysis}

DNA fragments of 1297 bp encompassing the gp120-C2 to the transmembrane gp41 region (positions 6999-8296 of the HIV-1 HXB2 genome $)^{21}$ were PCR amplified using ED31MM1 (first round) and ES7-MM4 (nested) primer sets to identify the putative recombination breakpoints among the gp120/gp41 discordant subtype samples. To cover the whole region, DNA sequencing was performed in both senses using primers ES7, ES8, ED12, ED14, ED31, and ED33 previously described $^{20}$ and MM2 (GTCTGGGGCATCAAGCAGCT/ HXB2 7931 to 7950), MM4, and MM5.

Identification of recombinant viruses was performed using the Recombinant Identification Program (RIP) from the Los Alamos Database webpage (http://hiv-web.lanl.gov/) and confirmed by the SimPlot for Windows version 2.5 (http://www. med.jhu.edu/deptmed/sray/download/). Recombinant breakpoint positions were based on the HXB2 genome (GenBank accession number K03455).

\section{RESULTS}

To provide phylogenetic relationship inferences among subtype samples prevalent in two Brazilian regions and to test the presence of recombinant viruses, a subset of $34 \mathrm{HIV}-1$ samples, previously subtyped by env-HMA, was selected for this study.

The phylogenetic analyses of PCR-amplified fragments of the gag p17 (360 bp), env C2-V3 (300 bp), env gp41 (480), and $n e f(660 \mathrm{bp})$ regions are presented in Figure 1. Discordant subtyping among the four regions was observed for nine (26.5\%) of 34 samples analyzed, suggesting the presence of potentially recombinant HIV-1 samples, which are underlined in the phylogenetic trees. All of the seven subtype B samples exhibited consistent phylogenetic groupings with the reference samples across their genome and were classified as potentially pure prototypic subtype B. The two previously env-HMA subtyped D samples were also classified as D regardless of the region analyzed. The one subtype A sample described in this study also grouped with subtype A references in both C2-V3 and gp41 env regions. One of the samples from southern Brazil 
(98BRRS004), classified as B" in the C2-V3 gp120 and as B in gp41 had the gag and nef regions clustering with subtype C. Two of seven C2-V3 subtype $\mathrm{C}$ samples presented recombinant patterns as Bgag/Cenv/Bnef (98BRRS028) and Bgag/ Cenv/Cnef (98BRRS035). Subtype F was highly variable exhibiting at least three distinct patterns. Indeed, from the eight samples subtyped as F based on the C2-V3 gp120, six seemed to be potentially recombinant viruses with genomes like Bgag/Fenv/Bnef (95BRMG005), Bgag/Fgp120/Bgp41/Bnef (96BRRJ101), Fgag/Fenv/Bnef (98BRRS037), Bgag/Fgp120/ Bgp41 (95BRRJ014 and 95BRSP004), and Bgag/Fgp120 (98BRRS053). Moreover, nef sequencing did not give usable sequences for some HIV-1 samples, suggesting a high polymorphism of the nef-targeted sequences. These results are summarized in Table 1, which also includes the geographic origin of the HIV-1 samples as well as the year of sample collection.

Phylogenetic tree analysis of the gp120 C2-V3 region showed that almost all of our samples clustered consistently with the subtype reference strains, and the major subtype branches presented high bootstrap values (Fig. 1B). Nine representative $\mathrm{B}^{\prime \prime}$ subtype B variant samples, bearing the GWGR sequence at the top of the V3 loop, clustered together in a separate group, although this clustering was not supported by a significant bootstrap value $(>70 \%)$. One of the $\mathrm{B}^{\prime \prime}$ samples (95BRSP001) was highly divergent, showing a 12 bp insertion at the top of the V3 loop in addition to several nucleotide substitutions. Sample 95BRRJ012, which presents the GFGR motif at the top of the V3 loop, also clustered together with the B" subtype B variant, probably as a consequence of the great genetic similarity among them. Indeed, the GWG motif (TGG) was suggested to be an intermediate sequence to GFG motif (TTG or TTT or TTC). ${ }^{29}$ The remaining subtype B samples clustered in another branch, with the exception of sample 95BRRJ002, which appeared alone in one separate branch. Sub-

Table 1. Summary of HIV-1 Subtyping of Brazilian HiV-1 Samples from Southeastern and Southern Regions Based on the Genetic Characterization of Distinct Genomic Regions

\begin{tabular}{|c|c|c|c|c|c|c|}
\hline Sample & State of origin ${ }^{\mathrm{a}}$ & $\begin{array}{l}\text { Date of } \\
\text { collection }\end{array}$ & $\begin{array}{l}\text { gag p-17 } \\
\text { genotype }\end{array}$ & $\begin{array}{c}C 2-V 3 \\
\text { genotype }\end{array}$ & $\begin{array}{c}\text { gp41 } \\
\text { genotype }\end{array}$ & $\begin{array}{c}\text { nef } \\
\text { genotype }\end{array}$ \\
\hline 95BRMG005 & Minas Gerais & 1995 & B & $\mathrm{F}$ & $\mathrm{F}$ & $\mathrm{B}$ \\
\hline 95BRRJ002 & Rio de Janeiro & 1995 & B & B & B & $\mathrm{B}$ \\
\hline 95BRRJ005 & Rio de Janeiro & 1995 & B & $\mathrm{B}$ & B & $\mathrm{B}$ \\
\hline 95BRRJ006 & Rio de Janeiro & 1995 & B & $\mathrm{B}^{\prime \prime}$ & B & B \\
\hline 95BRRJ008 & Rio de Janeiro & 1995 & B & $\mathrm{B}^{\prime \prime}$ & B & B \\
\hline 95BRRJ009 & Rio de Janeiro & 1995 & B & $\mathrm{B}^{\prime \prime}$ & B & $\mathrm{B}$ \\
\hline 95BRRJ011 & Rio de Janeiro & 1995 & $\mathrm{~B}$ & $\mathrm{~B}$ & $\mathrm{~B}$ & B \\
\hline 95BRRJ012 & Rio de Janeiro & 1995 & B & $\mathrm{B}$ & B & B \\
\hline 95BRRJ013 & Rio de Janeiro & 1995 & B & $\mathrm{B}^{\prime \prime}$ & B & B \\
\hline 95BRRJ014 & Rio de Janeiro & 1995 & $\mathrm{~B}$ & $\mathrm{~F}$ & $\mathrm{~B}$ & WS \\
\hline 95BRRJ015 & Rio de Janeiro & 1995 & $\mathrm{~B}$ & B & $\mathrm{B}$ & $\mathrm{B}$ \\
\hline 95BRRJ016 & Rio de Janeiro & 1995 & B & $\mathrm{B}^{\prime \prime}$ & B & NA \\
\hline 95BRRJ017 & Rio de Janeiro & 1995 & B & $\mathrm{B}^{\prime \prime}$ & B & $\mathrm{B}$ \\
\hline 95BRRJ019 & Rio de Janeiro & 1995 & B & $\mathrm{B}$ & B & $\mathrm{B}$ \\
\hline 95BRRJ020 & Rio de Janeiro & 1995 & $\mathrm{~B}$ & $\mathrm{~B}$ & $\mathrm{~B}$ & $\mathrm{~B}$ \\
\hline 95BRRJ021 & Rio de Janeiro & 1995 & $\mathrm{~F}$ & $\mathrm{~F}$ & $\mathrm{~F}$ & $\mathrm{~F}$ \\
\hline 95BRSP001 & São Paulo & 1995 & $\mathrm{~B}$ & $\mathrm{~B}^{\prime \prime}$ & $\mathrm{B}$ & $\mathrm{B}$ \\
\hline 95BRSP004 & São Paulo & 1995 & B & $\mathrm{F}$ & $\mathrm{B}$ & NA \\
\hline 95BRSP006 & São Paulo & 1995 & $\mathrm{C}$ & $\mathrm{C}$ & $\mathrm{C}$ & $\mathrm{C}$ \\
\hline 96BRRJ100 & Rio de Janeiro & 1996 & $\mathrm{D}$ & $\mathrm{D}$ & $\mathrm{D}$ & $\mathrm{D}$ \\
\hline 96BRRJ101 & Rio de Janeiro & 1996 & $\mathrm{~B}$ & $\mathrm{~F}$ & $\mathrm{~B}$ & $\mathrm{~B}$ \\
\hline 98BRRJ045 & Rio de Janeiro & 1998 & WS & $\mathrm{D}$ & $\mathrm{D}$ & $\mathrm{D}$ \\
\hline 98BRRS004 & Rio Grande do Sul & 1998 & $\mathrm{C}$ & $\mathrm{B}^{\prime \prime}$ & $\mathrm{B}$ & $\mathrm{C}$ \\
\hline 98BRRS006 & Rio Grande do Sul & 1998 & $\mathrm{~B}$ & $\mathrm{~B}^{\prime \prime}$ & $\mathrm{B}$ & WS \\
\hline 98BRRS010 & Rio Grande do Sul & 1998 & $\mathrm{C}$ & $\mathrm{C}$ & $\mathrm{C}$ & NA \\
\hline 98BRRS011 & Rio Grande do Sul & 1998 & $\mathrm{~F}$ & $\mathrm{~F}$ & $\mathrm{~F}$ & $\mathrm{~F}$ \\
\hline 98BRRS012 & Rio Grande do Sul & 1998 & $\mathrm{C}$ & $\mathrm{C}$ & $\mathrm{C}$ & WS \\
\hline 98BRRS022 & Rio Grande do Sul & 1998 & NA & $\mathrm{C}$ & $\mathrm{C}$ & WS \\
\hline 98BRRS028 & Rio Grande do Sul & 1998 & $\mathrm{~B}$ & $\mathrm{C}$ & $\mathrm{C}$ & $\mathrm{B}$ \\
\hline 98BRRS034 & Rio Grande do Sul & 1998 & NA & $\mathrm{C}$ & $\mathrm{C}$ & WS \\
\hline 98BRRS035 & Rio Grande do Sul & 1998 & $\mathrm{~B}$ & $\mathrm{C}$ & $\mathrm{C}$ & $\mathrm{C}$ \\
\hline 98BRRS037 & Rio Grande do Sul & 1998 & $\mathrm{~F}$ & $\mathrm{~F}$ & $\mathrm{~F}$ & $\mathrm{~B}$ \\
\hline 98BRRS053 & Rio Grande do Sul & 1998 & $\mathrm{~B}$ & $\mathrm{~F}$ & NA & NA \\
\hline 98BRRS058 & Rio Grande do Sul & 1998 & WS & $\mathrm{A}$ & A & WS \\
\hline
\end{tabular}

${ }^{a}$ Minas Gerais, Rio de Janeiro, and São Paulo are localized in southeastern Brazil whereas Rio Grande do Sul State is in the southern region. NA, not amplified; WS, without readble sequences. 
type C sample 98BRRS028, a possible recombinant virus (B gag/Cenv/Bnef), formed a separate single branch, closely related to the remaining $\mathrm{C}$ sample group.

Although the PCR amplification of subtype A sample 98BRRS058 was possible with all primer sets included in this study, usable sequences were obtained just for the gp120 and gp41 env regions. Phylogenetic analysis revealed that this sample appeared alone in one separate branch closely related to the subtype A reference strains in both regions (Fig. 1B and C).

No significant bootstrap values $(>70 \%)$ could be obtained for some of the major subtype branches in the phylogenetic analysis of the gag, C2-V3, gp41, and nef regions (Fig. 1). However, these values increased when highly divergent samples were excluded from the analysis. For instance, the bootstrap value obtained for the gp41 subtype F samples was $67 \%$, increasing to $81 \%$ when the 95BRMG005 sample was excluded from the analysis (Fig. 1C). Moreover, subtype B samples 98BRRS028, 95BRRJ009, and 98BRRS037 were highly divergent in the nef region (Fig. 1D), and their inclusion in the phylogenetic tree analysis reduced the bootstrap value of the $\mathrm{B}$ branch from 83 to $64 \%$ and, except for sample 95BRRJ009, further SimPlot analysis of this region suggested a B/F recombinant profile (data not shown).

Amplification of the 1298-bp fragment encoding the env C2-V3/gp41 region was obtained for three samples (95BRRJ014, 95BRSP004, and 96BRRJ101) showing discordant gp120 and gp41 subtypes to perform the characterization of putative recombination breakpoints based on the RIP and SimPlot 2.5 analyses. Figure $2 \mathrm{~A}$ is representative of the SimPlot analysis of those samples, including the CRF12 ARMA $185^{30}$ for comparative purposes. A schematic representation of the putative breakpoints of recombinant $\mathrm{B} / \mathrm{F}$ viruses is depicted in Figure 2B. Similar breakpoints were observed between unlinked samples 95BRRJ014 and 96BRRJ101. One of the breakpoints was localized in the gp120 C5 region, with a discrepancy of $20 \mathrm{bp}$, and the other was localized in the same position at the gp41 immunodominant epitope for both samples. Moreover, sample 95BRSP004 presented just one breakpoint, which was also localized in the gp120 C5 region close to the former ones.

Figure 3 shows the high complexity of the Brazilian subtype A sample 98BRRS058 based on the SimPlot analysis. Three fragments could be identified as subtype A, with at least $80 \%$ similarity with the A reference samples (hatched open boxes). However, no clear subtyping could be obtained for the intermediate fragments (open boxes), which gave high similarity values with distinct HIV-1 subtypes.

\section{DISCUSSION}

The presence of several HIV-1 subtypes circulating in Brazil has already been described by our group and others. ${ }^{9-19}$ In this paper we have tried to improve the molecular analysis of HIV1 samples obtained from two Brazilian regions, characterized by the presence of more than one prevalent subtype, to identify recombinant viruses. In fact, based on the phylogenetic analysis of $e n v \mathrm{C} 2-\mathrm{V} 3$ and gp41, gag p17, and nef regions, potentially HIV-1 recombinant viruses were found at a high rate $(26.5 \%)$ among 34 randomly selected samples. The great ma- jority (six of eight) of the potentially recombinant genomes were found among samples previously subtyped as $\mathrm{F}$ based on the env $\mathrm{C} 2-\mathrm{V} 3$ region. All of them were due to recombination between subtypes B and F. Subtype B and C recombinant viruses were also found in two of seven subtype $\mathrm{C}$ env samples from southern Brazil, with two distinct patterns (Bgag/Cenv/ Bnef and Bgag/Cenv/Cnef).

In a previous study, with HIV-1 samples collected between 1990 and 1992, we were able to identify one B/F recombinant virus in 28 samples obtained from patients also infected in the southeastern region of Brazil. ${ }^{9,15}$ However, in that study only the C2-V3 gp120 envelope region was analyzed limiting the identification of the recombination events. Indeed, it was estimated that around $10 \%$ of HIV-1 circulating forms in the world correspond to recombinant viruses. ${ }^{31}$ With the extension of the analysis to other genomic regions, in addition to the envelope gene, as well as of full genome sequences, it became evident that the frequency of subtype recombinant viruses is quite important in the AIDS pandemic. ${ }^{32}$ Recent studies from Africa show that the proportion of samples with gag/env discordant subtypes can vary from less than $10 \%$ to up to $40 \%$, according to the number of different subtypes found to be circulating in the region. ${ }^{33}$ In a study conducted in Manaus, Brazil, $45 \%$ of $\mathrm{B} / \mathrm{F}$ recombinant viruses were identified. ${ }^{34}$ Similar data were also observed in samples from other South American countries (Argentina, Uruguay, and Bolivia), where no pure subtype F was found. In fact, all subtype $F$ samples classified based on env HMA were found to be unique recombinant $\mathrm{B} / \mathrm{F}$ forms or represented a new circulating recombinant form, CRF12. ${ }^{30}$ This same study supports the evidence that these $\mathrm{B} / \mathrm{F}$ recombinants have been circulating since the beginning of the 1980s, showing that recombinant forms are viable and efficiently transmitted, as previously reported. ${ }^{15}$ Taken together, the available data concerning $\mathrm{B} / \mathrm{F}$ recombinant viruses suggest that subtype $\mathrm{F}$ samples could be more susceptible for the recombination events, or we can also suppose that $\mathrm{B} / \mathrm{F}$ recombination could improve virus infectiousness or increase the virus fitness, however biological studies should be made to confirm these hypotheses.

The three samples presenting discordant subtypes between gp120 and gp41 (95BRRJ014, 95BRSP004, and 96BRRJ101) were amplified in almost the full-length env $\mathrm{C} 2-\mathrm{V} 3 / \mathrm{gp} 41$ fragment. The analyses of this fragment allow us to verify two similar mosaic genomes (F gp120 C2-C5/B C5-gp41ID/F gp41 ID-3') for samples 95BRRJ014 and 96BRRJ101. A distinct mosaic genome was found for sample 95BRSP004, which presents only one breakpoint localized in the $\mathrm{C} 5 \mathrm{gp} 120$ region. All three samples were classified as B in the gag p17 region, and sample 96BRRJ101 was also classified as B in the nef region, thus differing from the CRF12 samples that are classified as F in these regions. Indeed, this circulating recombinant form, recently described for HIV-1 samples from Argentina and Uruguay, ${ }^{30}$ is classified as subtype $F$ in almost the entire gp160, with the exception of a small B segment located in the intracellular part of the gp41 protein (8483-8660), distinct from our samples, that is clearly $\mathrm{F}$ and $\mathrm{B}$ or $\mathrm{B} / \mathrm{F}$ in the gp120 and gp41 regions (Fig. 2). Thus, further studies of full length sequencing of these unlinked Brazilian $\mathrm{B} / \mathrm{F}$ recombinant viruses will be of paramount importance for the identification of new CRFs in South America. 
A

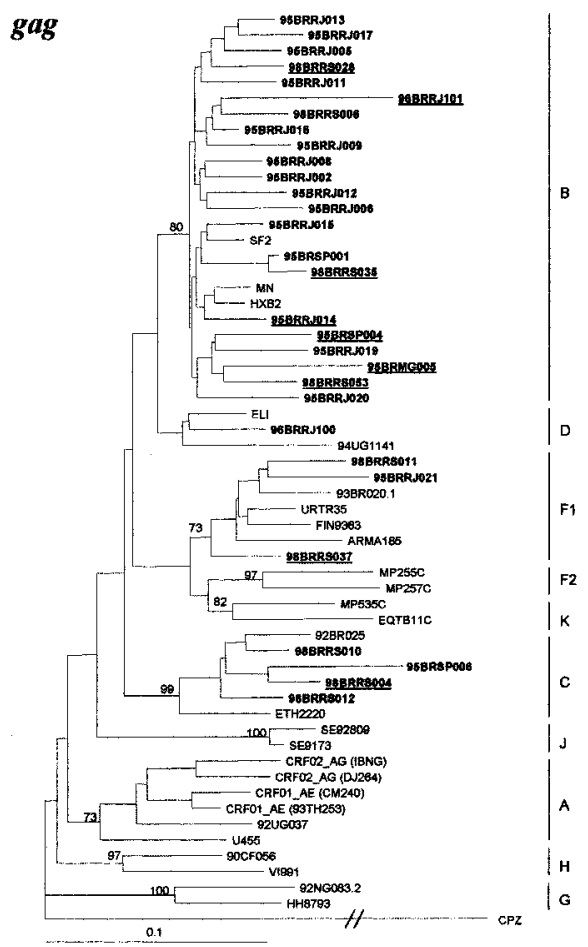

C

gp41

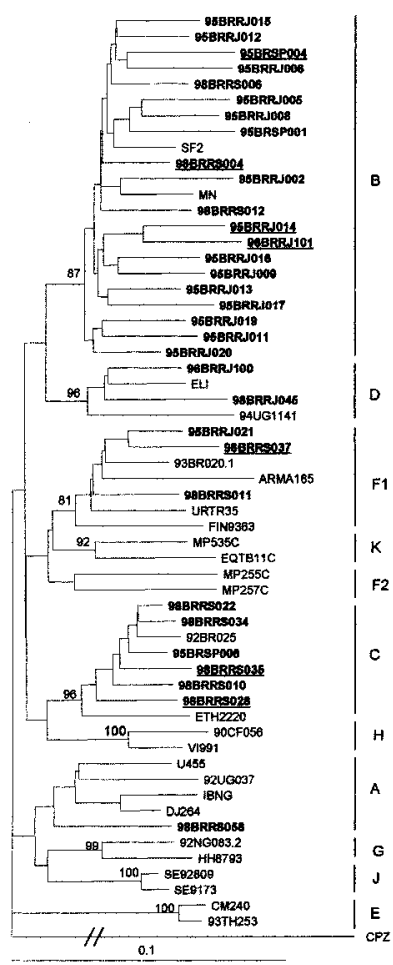

B
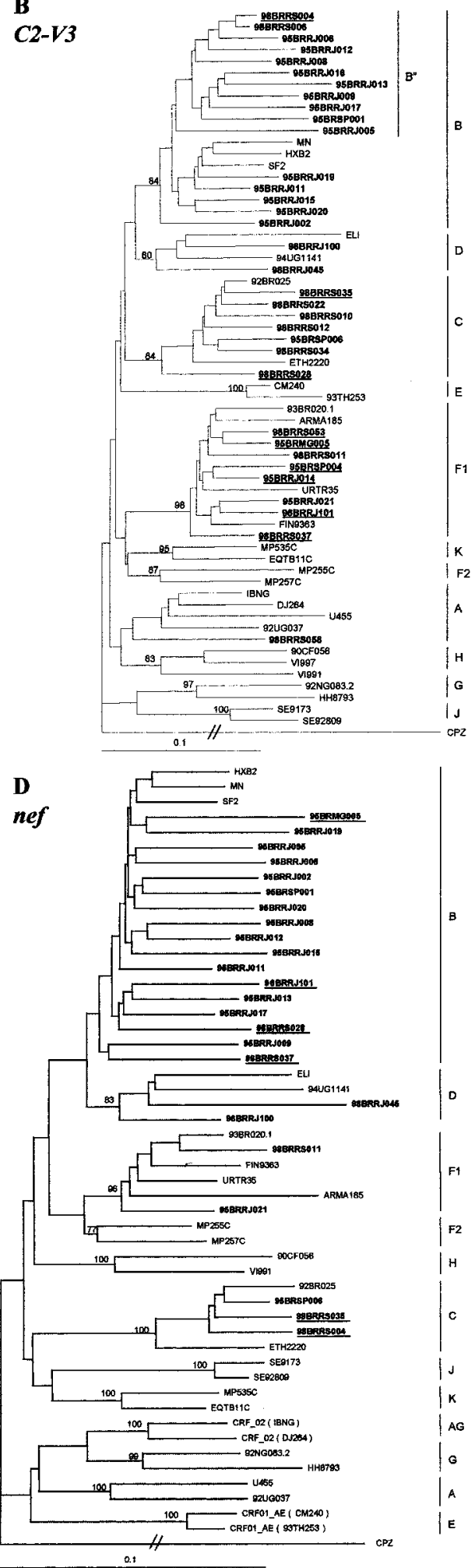

FIG. 1. Phylogenetic analysis of 34 HIV-1 samples from southeast and south regions of Brazil and reference HIV-1 group M subtypes available in the GenBank. The phenograms obtained from the alignments of the gag p17 (360 bp), env C2-V3 (300 bp) and gp41 (480 bp), and nef (660 bp) regions are represented, respectively, in $\mathbf{A}, \mathbf{B}, \mathbf{C}$, and $\mathbf{D}$. The sequence SIV $_{\mathrm{CPZGAB}}$ was used as outgroup. The bootstrap values for 100 replicates are indicated in the major subtype branches. The scale bar indicates $10 \%$ nucleotide sequence divergence. HIV-1 samples analyzed in the present study are indicated in bold and those presenting discordant subtyping are underlined. 
A)
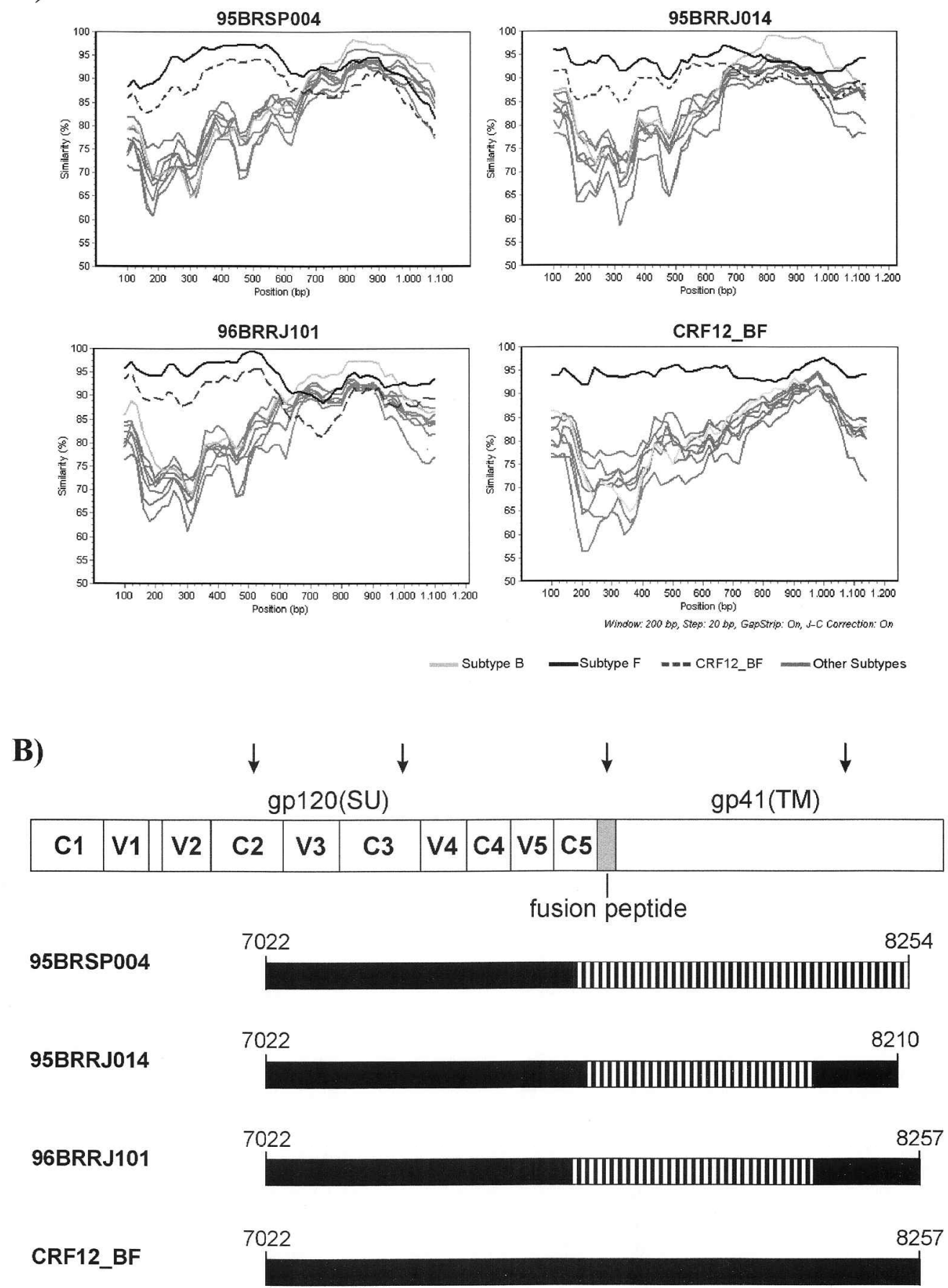

\section{Subtype F [II] Subtype B}

FIG. 2. C2V3-gp41 env recombinant B/F samples among Brazilian HIV-1 samples. (A) SimPlot analysis of the three Brazilian HIV-1 B/F recombinant samples and one representative CRF-12 virus compared to the subtype consensus reference sequences from Los Alamos Database. The search was made in windows of $200 \mathrm{bp}$, with a threshold of $90 \%$ for statistical confidence. Gaps were stripped. The $x$ axis shows the nucleotide position along the alignment. The $y$ axis indicates the similarity index between the HIV-1 subtype nucleotide sequences. (B) Schematic representation of the putative breakpoints within the C2-V3/gp41 region of recombinant B/F viruses based on RIP and SimPlot 2.5 program analyses. The breakpoint positions are based on the HXB2 genome. The arrows indicate the corresponding $\mathrm{C} 2-\mathrm{V} 3$ and gp41 env segments analyzed in Figure $1 \mathrm{~B}$ and $\mathrm{C}$. 


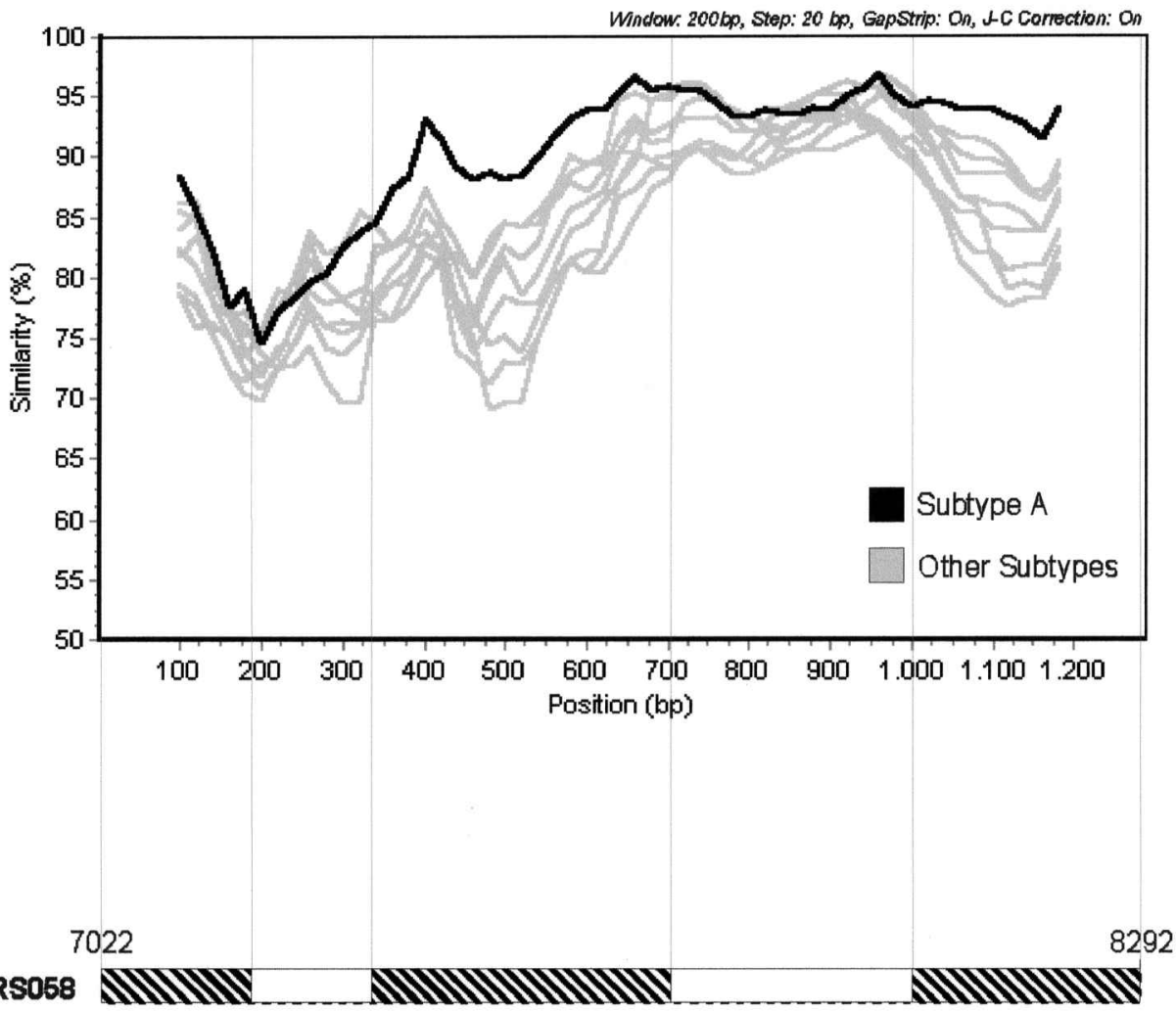

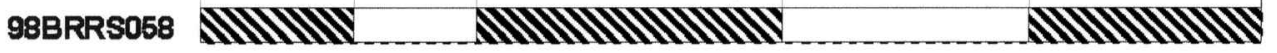

\section{N Subtype A \\ Unclassified}

FIG. 3. High complexity of the Brazilian subtype A sample 98BRRS058. At least four putative recombinant breakpoints can be depicted in the C2-V3/gp41 region. Fragments were identified as unclassified when no clear subtyping was obtained with RIP and SimPlot programs or based on the phylogenetic tree analysis of those fragments. SimPlot conditions were the same as described for Figure 2.

The study of HIV-1 subtype $\mathrm{C}$ samples has been considered quite important for vaccine development. This subtype corresponded to $56 \%$ of the new HIV-1 infections in $1999^{35}$ and seems to be spreading all over the world. Three circulating recombinant forms involving subtype $\mathrm{C}$ samples have already been described ${ }^{32,36,37}$ Recombination between subtypes B and $\mathrm{C}$ has been identified among the HIV-1 samples obtained from southern Brazil described in the present study, with at least three distinct patterns (Bgag/Cenv/Bnef, Bgag/Cenv/Cnef, and $\mathrm{C} g a g / \mathrm{B} e n v / \mathrm{Cnef}$ ). In a previous study, ${ }^{22}$ a $\mathrm{Cgag} / \mathrm{B} e n v$ recombinant pattern was also detected among Brazilian HIV-1 samples collected in the southern region, in a setting of a UNAIDS initiative for HIV-1 subtyping in potential HIV-1 vaccine trial sites, suggesting that recombinant $\mathrm{B} / \mathrm{C}$ genomes can be quite extensively spread in this region.

In contrast to the low number of subtype $C$ samples already described for other Brazilian regions, ${ }^{11,38,39}$ a high prevalence of this subtype has been found in the south. ${ }^{13}$ The mean distance of $10.5 \%$ verified in the $\mathrm{C} 2-\mathrm{V} 3$ region among subtype $\mathrm{C}$ samples described in the present work supports the recent introduction of this subtype in the country, as previously pro- posed. ${ }^{40}$ In contrast, the highest distance diversity was observed within subtype B samples in all genomic regions included in the present analysis, suggesting that this subtype has been circulating in Brazil for a longer period of time, with multiple virus introductions.

The presence of HIV-1 subtypes D and A has been recently documented in Brazil. ${ }^{17-19}$ In this paper we described an imported case of subtype D infection in a sample from southeastern Brazil, found in a patient infected in Africa (98BRRJ045), which presented a high molecular distance when compared to the autochthonousBrazilian subtype D sample previously documented by our group (96BRRJ100). ${ }^{18}$ The HIV-1 subtype A sample analyzed in this study was identified in a molecular epidemiological survey carried out in southern Brazil (98BRRS058), as presenting an indeterminate env HMA pattern, being further subtyped based on the phylogenetic analysis of the $\mathrm{C} 2-\mathrm{V} 3$ region. Moreover, the SimPlot analysis of the 1290-bp fragment covering the env C2-V3/gp41 region showed three distinct segments that did not match specifically with any of the known subtypes. This might explain the isolated branching of this sample near the subtype A reference samples in the 
phylogenetic tree analysis of this fragment. The presence of this subtype in Brazil was firstly described in an HIV-1 sample from Rio de Janeiro based on the analysis of the gag p24 region. ${ }^{19}$ The RT-pol region was also analyzed in this paper, but it could not be assigned to any specific subtype group. Taken together, these "subtype A" samples, identified in two distant Brazilian regions, could represent new subtype A variants to be explored in further analysis. The potential role of these subtypes and recombinant genomes in different aspects of the AIDS epidemics is still a matter of investigation.

\section{SEQUENCE DATA}

GenBank accession numbers: AY071929-AY071952 (nef gene), AY071953-AY071967 (C2-V3 env gene), AY071968AY071996 ( $g a g$ gene), AY01997-AY072000 (GP160 env gene), AF463420-AF463458 (gp41 env gene). AF062422 (95BRMG005,C2-V3), AF062424 (95BRRJ014, C2-V3), AF062425 (95BRRJ021), AF060953 (95BRRJ002), AF060955AF060962 (95BRRJ005-95BRRJ13), AF060963-AF060967 (95BRRJ015-95BRRJ020), AF062425 (95BRRJ021), AF000238 (96BRRJ100).

\section{ACKNOWLEDGMENTS}

The HIV-1 env Subtyping Kit was kindly provided by the NIH AIDS Research and Reference Reagent Program and UNAIDS. M.L. Guimarães was personally supported by a grant from CAPES. Supported by the National Coordination of STD/AIDS/UNDP/World Bank (UNAIDS), PIAF/FIOCRUZ/ Ministry of Health, FAPERJ, and the Brazilian Research Council $(\mathrm{CNPq})$. Fiocruz is a UNAIDS Collaborative Centre. The Brazilian Network for HIV Isolation and Characterization: L.F.M. Brígido, D. Greco, and M. I. Linhares de Carvalho.

\section{REFERENCES}

1. Brazilian Ministry of Health: Boletim Epidemiológico-Aids. July-September 2001, No. 1 (in portuguese).

2. Gurtler LG, Hauser PH, Eberle J, von Brunn A, Knapp S, Zekeng L, Tsague JM, and Kaptue L: A new subtype of human immunodeficiency virus type 1 (MVP-5180) from Cameroon. J Virol 1994;68(3):1581-1585.

3. Simon F, Mauclere P, Roques P, Loussert-Ajaka I, Müller-Trutwin MC, Saragosti S, Georges-Courbot MC, Barre- Sinoussi F, and Brun-Vezinet F: Identification of a new human immunodeficiency virus type 1 distinct from group $\mathrm{M}$ and $\mathrm{O}$. Nature Med 1998;4:1032-1037.

4. Gao F, Bailes E, Robertson DL, Chen Y, Rodenburg CM, Michael SF, Cummins LB, Arthur LO, Peeters M, Shaw GM, Sharp PM, and Hahn BH: Origin of HIV-1 in the chimpanzee Pan troglodytes troglodytes. Nature 1999;379:436-441.

5. Corbet S, Müller-Trutwin MC, Versmisse P, Delarue S, Ayouba A, Lewis J, Brunak S, Martin P, Brun-Vezinet F, Simon F, BarreSinoussi $\mathrm{F}$, and Mauclere $\mathrm{P}$ : env sequences of simian immunodeficiency viruses from chimpanzees in Cameroon are strongly related to those of human immunodeficiency virus group $\mathrm{N}$ from the same geographic area. J Virol 2000;74(1):529-534.

6. Triques K, Bourgeois A, Vidal N, Mpoudi-Ngole E, Mulanga-
Kabeya C, Nzilambi N, Torimiro N, Saman E, Delaporte E, and Peeters M: Near-full-length genome sequencing of divergent African HIV type 1 subtype F viruses leads to the identification of a new HIV type 1 subtype designated K. AIDS Res Hum Retroviruses 2000;16:139-151.

7. Gao F, Vidal N, Li Y, Trask SA, Chen Y, Kostrikis LG, Ho DD, Kim J, Oh MD, Choe K, Salminen M, Robertson DL, Shaw GM, Hahn BH, and Peeters M: Evidence of two distinct subsubtypes within the HIV-1 subtype A radiation. AIDS Res Hum Retroviruses 2001;17(8):675-688.

8. Robertson DL, Anderson JP, Bradac JA, Carr JK, Foley B, Funkhouser RK, Gao F, Hahn BH, Kalish ML, Kuiken C, Learn GH, Leitner T, McCutchan F, Osmanov S, Peeters M, Pieniazek D, Salminen M, Sharp PM, Wolinsky S, and Korber B: HIV-1 nomenclature proposal. Science 2000;288(5463):55-56.

9. Morgado MG, Sabino E, Sphaer E, Bongertz V, Brigido L, Guimaraes MD, Castilho EA, Galvão-Castro B, Mullins JI, Hendry $\mathrm{RM}$, and Mayer A: V3 region polymorphisms in HIV-1 from Brazil: Prevalence of subtype B strains divergent from North American/European prototype and detection of subtype F. AIDS Res Hum Retroviruses 1994;10:569-576.

10. WHO Network for HIV Isolation and Characterization: HIV type I variation in World Health Organization-sponsored vaccine evaluation sites: Genetic screening, sequence analysis, and preliminary biological characterization of selected viral strains. AIDS Res Hum Retroviruses 1994;10:1327-1343.

11. Brazilian Network for the HIV-1 Isolation and Characterization (Bongertz V, Bou-Habib DC, Brígido LFM, Caseiro M, Chequer PJN, Couto-Fernandez JC, Ferreira PC, Galvão-Castro B, Greco D, Guimarães ML, Linhares de Carvalho MI, Morgado MG, Oliveira CAF, Osmanov S, Ramos CA, Rossini M, Sabino E, Tanuri A, and Ueda M): HIV-1 diversity in Brazil: Genetic, biologic and immunologic characterization of HIV-1 strains in three potential HIV vaccine evaluation sites. J Acquir Immune Defic Syndr 2000;23:184-193.

12. Guimarães ML, Bastos FI, Telles PR, Galvão-Castro B, Diaz RS, Bongertz V, and Morgado MG: Retrovirus infections in a sample of injecting drug users in Rio de Janeiro City, Brazil: Prevalence of HIV-1 subtypes, and co-infection with HTLV-I/II. J Clin Virol 2001;21:143-151.

13. Loureiro R, Casseb JS, Bongertz V, Asquidanini S, Bet E, Silveira VLB, and Dias CS: Seroreactivity to HIV-1 peptides in pregnant women in Porto Alegre, RS State, Brazil. 12th World AIDS Conference Geneva, June 28-July 3. Conference Record 1998, p. 22.

14. Morgado MG, Guimarães ML, Neves I Jr, dos Santos VG, Linhares-de-Carvalho MI, Castello-Branco LR, Bastos FI, Castilho EA, Galvão-Castro B, Bongertz V, and The Hospital Evandro Chagas AIDS Clinical Research Group: Molecular epidemiology of HIV in Brazil: Polymorphism of the antigenically distinct HIV-1 B subtype strains. Mem Inst Oswaldo Cruz 1998;93:383-386.

15. Sabino EC, Shpaer EG, Morgado MG, Kober BT, Diaz RS, Bongertz V, Cavalcante S, Galvão-Castro B, Mullins JI, and Mayer A: Identification of human immunodeficiency virus type 1 envelope genes recombinant between subtypes $\mathrm{B}$ and $\mathrm{F}$ in two epidemiologically linked individuals from Brazil. J Virol 1994;68: 6340-6346.

16. Janini LM, Pieniazek D, Peralta JM, Schechter M, Tanuri A, Vicente AC, dela Torre N, Pieniazek NJ, Luo CC, Kalish ML, Schochetman G, Rayfield MA: Identification of single and dual infections with distinct subtypes of human immunodeficiency virus type 1 by using restriction fragment length polymorphism analysis. Virus Genes 1996;13:69-81.

17. Tanuri A, Swanson P, Devare S, Berro OJ, Savedra A, Costa LJ, Telles JG, Brindeiro R, Schable C, Pieniazek D, and Rayfield M: HIV-1 subtypes among blood donors from Rio de Janeiro, Brazil. J Acquir Immune Defic Syndr Hum Retrovirol 1999;20(1):60-66. 
18. Morgado MG, Guimarães ML, Gripp CB, Costa CI, Neves I Jr, Veloso VG, Linhares-de-Carvalho MI, Castello-Branco LR, Bastos FI, Kuiken C, Castilho EA, Galvão-Castro B, Bongertz V, and The Hospital Evandro Chagas AIDS Clinical Research Group: Molecular epidemiology of HIV-1 in Brazil: High prevalence of HIV1 subtype $B$ and identification of an HIV-1 subtype D infection in the City of Rio de Janeiro, Brazil. J Acquir Immune Defic Syndr 1998;18:488-494.

19. Caride E, Brindeiro R, Hertogs K, Larder B, Dehertogh P, Machado E, Sá CA, Eyer-Silva WA, Sion FS, Passioni LF, Menezes JA, Calazans A, and Tanuri A: Drug-resistant reverse transcriptase genotyping and phenotyping $\mathrm{B}$ and non-B subtypes ( $\mathrm{F}$ and $\mathrm{A})$ of human immunodeficiency virus type 1 found in Brazilian patients falling HAART. Virology 2000;275(1):107-115.

20. Delwart EL, Herring B, Learn GH Jr, et al.: Heteroduplex mobility analysis HIV-1 env Subtyping Kit. Protocol Version 3 1995, NIH AIDS Research and Reference Program.

21. Ratner L, HaseltineW, Patarca R, Livak KJ, Starcich B, Josephs SF, Doran ER, Rafalski JA, Whitehorn EA, Baumeister K, Ivanoff L, Petteway SR Jr, Pearson ML, Lautenberger JA, Papas TS, Ghrayeb J, Chang NT, Gallo RC, and Wong-Staal F: Complete nucleotide sequence of the AIDS virus, HTLV-III. Nature 1985;313(6000):277-284.

22. Cornelissen M, Kampinga G, Zorgdrager F, Goudsmit J, and the UNAIDS Network for HIV Isolation and Characterization: Human immunodeficiency virus type 1 subtypes defined by env show high frequency of recombinant gag genes. J Virol 1996;70(11): 8209-8212.

23. Zazzi M, Romano L, Brasini A, and Valensin PE: Simultaneous amplification of multiple HIV-1 DNA sequences from clinical specimens by using nested-primer polymerase chain reaction. AIDS Res Hum Retroviruses 1993;39(4):315-320.

24. Artenstein AW, Hegerich PA, Beyrer C, Rungruengthanakit K, Michael NL, and Natpratan C: Sequences and phylogenetic analysis of the nef gene from Thai subjects harboring subtype E HIV1. AIDS Res Hum Retroviruses 1996;12(6):557-560.

25. GCG-Sequence Analysis Software Package, University of Winsconsin Genetics Computer Group 1996; Inc. version 9.0.

26. Thompson J, Higgins D, and Gibson T: CLUSTAL W: Improving the sensitivity of progressive multiple sequence alignment through sequence weighting, position-specific gap penalties and weight choice. Nucleic Acids Res 1994;22:4673-4680.

27. Saitou N and Nei M: The neighbor-joining method: A new method for reconstructing phylogenetic trees. Mol Biol Evol 1987; 74:406-425.

28. Page RD: TreeView: An amplication to display phylogenetic trees on personal computers. Comput Appl Biosci 1996;12:357-358.

29. Covas DT, Biscaro TA, Kashima S, Duarte G, and Machado AA: High frequency of the GWG (Pro Trp) envelope variant of HIV-1 in Southeast Brazil. J Acquir Immune Defic Syndr Hum Retrovirol 1998;19:74-79.

30. Carr JK, Avila M, Gomez Carrillo M, Salomon H, Hierholzer J, Watanaveeradej V, Pando MA, Negrete M, Russell KL, Sanchez
J, Birx DL, Andrade R, Vinoles J, and McCutchan FE: Diverse BF recombinants have spread widely since the introduction of HIV-1 into South America. AIDS 2001;15(15):F41-F47.

31. McCutchan FE, Salminen MO, Carr JK, and Burke DS: HIV-1 genetic diversity. AIDS 1996;10(Suppl. 3):S13-S20.

32. McCutchan FE: Understanding the genetic diversity of HIV-1. AIDS 2000;14(Suppl.3):S31-S44.

33. Peeters M: Recombinant HIV sequences: Their role in the global epidemic. In: Human Retrovirus and AIDS. Los Alamos National Laboratory, Los Alamos, NM, 2000, pp. I39-I54.

34. Vicente AC, Otsuki K, Silva NB, Castilho MC, Barros FS, Pieniazek D, Hu D, Rayfield MA, Bretas G, and Tanuri A: The HIV epidemic in the Amazon Basin is driven by prototypic and recombinant HIV-1 subtypes B and F. J Acquir Immune Defic Syndr 2000;23:327-331.

35. Esparza $\mathrm{J}$ and Bhamarapravati $\mathrm{N}$ : Accelerating the development and future availability of HIV-1 vaccines: Why, when, where and how? Lancet 2000;355:2061-2066.

36. Su L, Graf M, Zhang Y, von Briesen H, Xing H, Kostler J, Melzl $\mathrm{H}$, Wolf $\mathrm{H}$, Shao $\mathrm{Y}$, and Wagner R: Characterization of a virtually full-length human immunodeficiency virus type 1 genome of a prevalent intersubtype $\left(\mathrm{C} / \mathrm{B}^{\prime}\right)$ recombinant strain in China. Virology 2000;74(23):11367-11376.

37. Koulinska IN, Ndung'u T, Mwakagile D, Msamanga G, Kagoma C, Fawzi W, Essex M, and Renjifo B: A new human immunodeficiency virus type 1 circulating recombinant form from Tanzania. AIDS Res Hum Retroviruses 2001;7(5):423-431.

38. Rossini MA, Diaz RS, Caseiro M, Turcato G, Accetturi CA, and Sabino EC: HIV-1 subtypes among intravenous drug users from two neighboring cities in São Paulo State, Brazil. Braz J Med Biol Res 2001;34:45-47.

39. Stefani MM, Pereira GA, Martelli CM, Shindo N, and Galvão-Castro B: Evidence of HIV-1 genetic diversity among pregnant women with AIDS or infected with HIV-1 in Central Brazil: J Acquir Immune Defic Syndr 2000;23(2):205-207.

40. Rodenburg CM, Li Y, Trask SA, Chen Y, Decker J, Robertson DL, Kalish ML, Shaw GM, Allen S, Hanh BH, Gao F, and The UNAIDS and NIAID Networks for Isolation and Characterization: Near full-length clones and reference sequences for subtype $\mathrm{C}$ isolates of HIV type 1 from three different continents. AIDS Res Hum Retroviruses 2000;17(2):161-168.

Address reprint requests to: Mariza G. Morgado Laboratory of AIDS and Molecular Immunology Department of Immunology Oswaldo Cruz Institute/FIOCRUZ Av Brasil 4365

Manguinhos Rio de Janeiro RJ, Brazil CEP 21045-900

E-mail: mmorgado@ioc.fiocruz.br 